Case Report

\title{
A Case of Neglected Bilateral Anterior Shoulder Dislocation: A Rare Entity with Unusual Mechanism of Injury
}

\author{
Raghuram Choulapalle, Ramu Chokkarapu, Ravi Kanth Kolluri, Sreedhar Reddy Anne, \\ Shanmuga Raju Perumal, Pavan Kumar Avadhanam, and Ramesh Bheemanathuni
}

Department of Orthopaedics \& Traumatology and Rehabilitation, Chalmeda Anand Rao Institute of Medical Sciences, Karimnagar, Telangana 505001, India

Correspondence should be addressed to Raghuram Choulapalle; raghuramchoulapalle@gmail.com

Received 27 August 2014; Revised 21 January 2015; Accepted 22 January 2015

Academic Editor: Dominique Saragaglia

Copyright (c) 2015 Raghuram Choulapalle et al. This is an open access article distributed under the Creative Commons Attribution License, which permits unrestricted use, distribution, and reproduction in any medium, provided the original work is properly cited.

\begin{abstract}
Bilateral shoulder dislocations are rare, and if they occurred, posterior type of dislocations is common. Bilateral anterior shoulder dislocations are very rare and occur due to trauma with unique mechanism of injury. We report a case of unreduced simultaneous bilateral anterior dislocations of shoulder without associated fractures in a forty-year-old man following a unique mechanism of injury; both hands of the patient were pulled from either side. To the best of our knowledge, this unusual mechanism of injury has not been reported in the literature.
\end{abstract}

\section{Introduction}

Anterior glenohumeral dislocations are most commonly encountered major joint dislocations in emergency room. Bilateral shoulder dislocations with or without fractures are rare. For a simultaneous bilateral dislocation to occur, the forces must act synchronously on both shoulders in a similar manner. Bilateral posterior dislocations are commonly seen during electrocution, convulsions, or hypoglycemic seizures due to violent contractions of internal rotators of shoulder. There are few reported cases of bilateral anterior shoulder dislocations with different mechanisms of injury: at the start of backstroke swimming competition, bench pressing athlete, fall on elbows, postseizure episode, trying to prevent a backward fall by extending both arms behind the back, and, in our case, pulling of both hands from either side with both limbs in abduction and external rotation.

\section{Case Report}

A forty-year-old man presented to our hospital in December 2013 with pain and restricted range of movements in both shoulders. Patient was involved in a quarrel six weeks back and both the hands of the patient were held by two people on either side and were pulled. He had no history of seizures, previous shoulder dislocations, or laxity of other joints. On examination, arms were abducted and externally rotated. There was loss of round contour of shoulder with fullness over anterior aspect of both shoulders. No neurovascular injury and no associated fractures were confirmed by radiographs and CT scan in both arms (Figures 1 and 3). Patient was able to perform flexion up to 30 degrees and abduction and external rotation with no pain restraint. Adduction and internal rotations were restricted (Figure 1).

Old unreduced dislocations are difficult to reduce by closed methods because of soft tissue contractures, fibrous tissue in the glenoid cavity, retracted rotator cuff muscle, iatrogenic fractures, and neurovascular damage. Left shoulder was operated on six weeks back. Soft tissue release and open reduction of the head into glenoid cavity was done through deltopectoral approach and secured with k-wires (Figure 2).

\section{Discussion}

Unilateral anterior shoulder dislocations account for 95\% of all shoulder dislocations, but simultaneous bilateral anterior dislocations are a clinical rarity because almost always one 


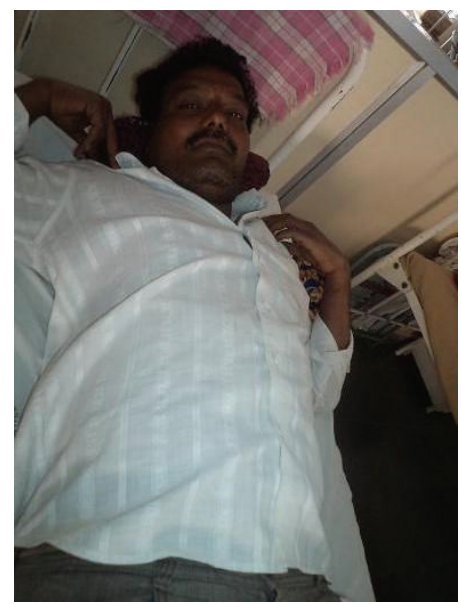

FIGURE 1: Patient with bilateral anterior shoulder dislocation.

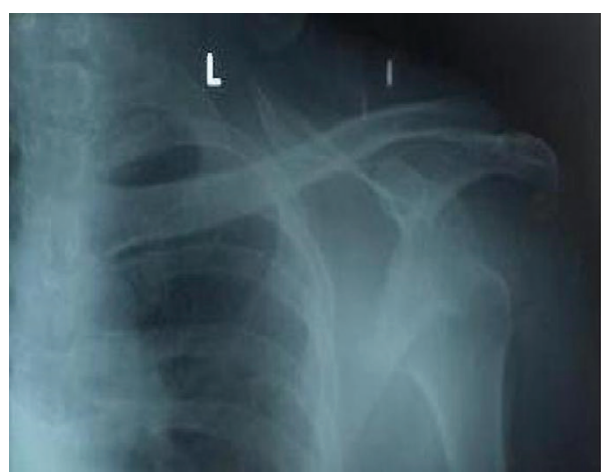

(a)

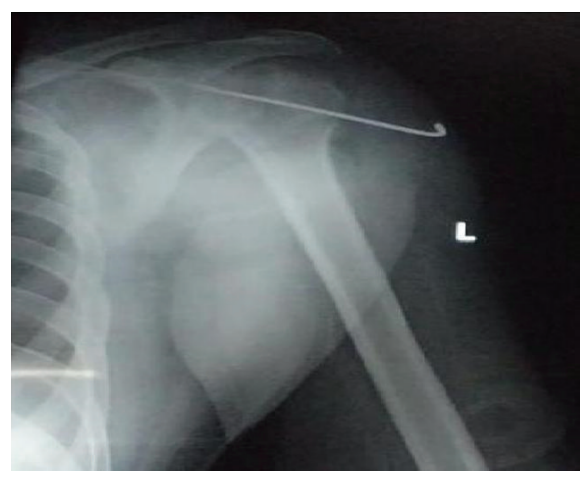

(b)

FIGURE 2: Radiographs of left anterior dislocation of shoulder (preoperative and postoperative).

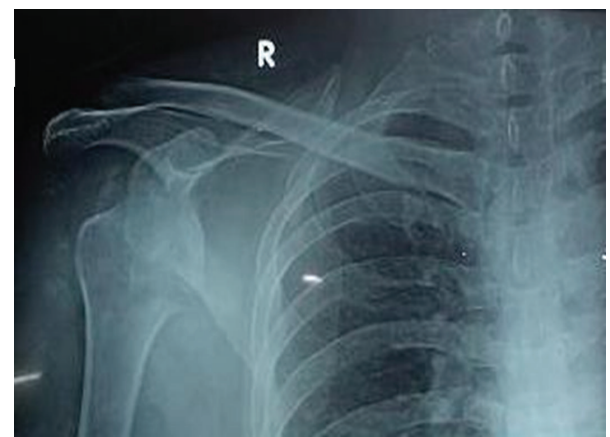

FIGURE 3: Radiographs of right anterior shoulder dislocation (preoperative).

extremity takes the brunt of impact during trauma incidence [1]. Axial loading with arm in internal rotation and adduction produces posterior dislocation, which is common in electrical shock or postseizure episode due to violent contraction of internal rotators of shoulder. Mechanism of bilateral anterior dislocation is combination of forced extension, abduction, and external rotation of both arms and these forces need to be symmetrical and simultaneous. Acute bilateral anterior dislocations have to be reduced quickly with various closed methods: the Stimson gravity method, Kocher maneuver, or Milch maneuver. Unreduced bilateral anterior dislocations cannot be reduced by closed methods because of fibrous tissue in glenoid cavity, risk of iatrogenic fractures, soft tissue interposition, and neurovascular damage.

Simultaneous bilateral anterior shoulder dislocations are rare. They have a unique mechanism of injury and were first described in 1902 in patients in whom excessive muscular contraction occurred as a result of camphor overdose by Mynter [2]. Cresswell in 1998 reported a case of bilateral anterior dislocation of the shoulder without any fractures in a bench pressing athlete [3]. Lasanianos and Mouzopoulos in 2008 reported a case of bilateral anterior dislocation of the shoulders after a seizure episode [4]. Turhan and Demirel in 2008 reported a bilateral anterior dislocation case in a horse rider [5], Felderman et al. in 2009 reported a similar case in a 44-year-old woman who was doing chin-up exercise [6], Thakur et al. reported a similar case where patient was trying to prevent a backward fall by extending both arms behind his back [7], Dlimi et al. in 2012 reported a case of bilateral anterior dislocation of the shoulders at the start of a backstroke swimming competition [8], and Yashwantha et al. in 2013 reported a similar case due to a fall over pointed 
TABLE 1: Different mechanism of injury in bilateral, simultaneous anterior shoulder dislocation.

\begin{tabular}{|c|c|c|c|c|c|}
\hline Author & Journal & Year & Associated fractures & Systemic diseases & Mechanism of injury \\
\hline Cresswell [3] & British Journal & 1998 & Nil & Nil & Bench pressing \\
\hline Jarvela and Salmela [1] & $\begin{array}{l}\text { SICOT online report } \\
\text { E028 }\end{array}$ & 2003 & $\begin{array}{l}\text { Humeral neck fracture } \\
\text { and rotator cuff tear on } \\
\text { left side }\end{array}$ & Nil & $\begin{array}{l}\text { Convulsions form } \\
\text { hypoglycemic shock }\end{array}$ \\
\hline Devalia and Peter [10] & J Postgrad Med & 2005 & $\begin{array}{l}\text { Greater tuberosity } \\
\text { fracture right side }\end{array}$ & Nil & $\begin{array}{l}\text { Landing on either side of } \\
\text { ladder on his out stretched } \\
\text { hands }\end{array}$ \\
\hline $\begin{array}{l}\text { lasanianos and } \\
\text { Mouzopoulos [4] }\end{array}$ & Cases Journal & 2008 & $\begin{array}{l}\text { Greater tuberosity } \\
\text { fracture and Hill-Sachs } \\
\text { lesion }\end{array}$ & Seizure disorder & Violent muscle contraction \\
\hline Turhan and Demirel [5] & $\begin{array}{l}\text { Arch Orthop Trauma } \\
\text { Surg }\end{array}$ & 2008 & Nil & Nil & Horse riding \\
\hline Abalo et al. [11] & E. pub & 2008 & Nil & Nil & Fall \\
\hline Felderman et al. [6] & $\begin{array}{l}\text { Journal of Emergency } \\
\text { Medicine }\end{array}$ & 2009 & Nil & Nil & Chin-up exercises \\
\hline Thakur et al. [7] & $\begin{array}{l}\text { Journal of Clinical and } \\
\text { Diagnostic Research }\end{array}$ & 2010 & Nil & Nil & $\begin{array}{l}\text { Backward fall by extending } \\
\text { both arms behind his back }\end{array}$ \\
\hline Mofidi et al. [12] & $\begin{array}{l}\text { American Journal of } \\
\text { Emergency Medicine }\end{array}$ & 2010 & $\begin{array}{l}\text { Temporomandibular } \\
\text { dislocation }\end{array}$ & $\begin{array}{c}\text { Generalized } \\
\text { tonic-clonic seizure }\end{array}$ & Violent muscle contraction \\
\hline Silva et al. [13] & Rev Bras Ortop & 2011 & Nil & Nil & Posterior fall \\
\hline Dlimi et al. [8] & J Orthop Traumatol & 2012 & Nil & Nil & $\begin{array}{l}\text { Backstroke swimming } \\
\text { competition }\end{array}$ \\
\hline Yashwantha et al. [9] & $\begin{array}{l}\text { Journal of Orthopaedic } \\
\text { Case Reports }\end{array}$ & 2013 & Nil & Nil & Fall on pointed elbows \\
\hline Our case & & & Nil & Nil & $\begin{array}{l}\text { Pulling of both hands on } \\
\text { either side }\end{array}$ \\
\hline
\end{tabular}

elbows [9]. In our case, it was pulling of both hands on either side, with both arms in abduction and external rotation, which is a unique mechanism of injury never described in the literature (Table 1).

\section{Conflict of Interests}

The authors declare that there is no conflict of interests regarding the publication of this paper.

\section{References}

[1] T. Jarvela and M. Salmela, "Bilateral anterior shoulder dislocation and fracture of the humeral neck combined with a large rotator cuff tear on left side," SICOT Online Report E028, 2003.

[2] H. Mynter, "Subacromial dislocation from muscular spasm," Annals of Surgery, vol. 36, no. 1, pp. 117-119, 1902.

[3] T. R. Cresswell, "Bilateral anterior shoulder dislocations in bench pressing: an unusual cause," British Journal of Sports Medicine, vol. 32, no. 1, pp. 71-72, 1998.

[4] N. Lasanianos and G. Mouzopoulos, "An undiagnosed bilateral anterior shoulder dislocation after a seizure: a case report," Cases Journal, vol. 1, article 342, 2008.

[5] E. Turhan and M. Demirel, "Bilateral anterior glenohumeral dislocation in a horse rider: a case report and a review of the literature," Archives of Orthopaedic and Trauma Surgery, vol. 128, no. 1, pp. 79-82, 2008.
[6] H. Felderman, R. Shih, and V. Maroun, "Chin up induced bilateral anterior shoulder dislocation," Journal of Emergency Medicine, vol. 37, no. 4, pp. 400-402, 2009.

[7] A. Thakur, R. Gupta, V. Kotwal, and D. Arora, "A rare case of bilateral anterior dislocation of the shoulder," Journal of Clinical and Diagnostic Research, vol. 4, no. 6, pp. 3567-3569, 2010.

[8] F. Dlimi, A. Rhanim, A. Lahlou et al., "Bilateral anterior dislocation of the shoulders at the start of a backstroke competition," Journal of Orthopaedics and Traumatology, vol. 13, no. 1, pp. 4749, 2012.

[9] K. C. Yashwantha, K. B. Nalini, M. Lalit, and P. Nagaraj, "Bilateral traumatic anterior dislocation of shoulder: a rare entity," Journal of Orthopaedic Case Reports, vol. 3, no. 1, pp. 2325, 2013.

[10] K. L. Devalia and V. K. Peter, "Bilateral post traumatic anterior shoulder dislocation," Journal of Postgraduate Medicine, vol. 51, no. 1, pp. 72-73, 2005.

[11] A. Abalo, A. Dossim, B. Songne et al., "Bilateral anterior dislocation of the shoulders: a case report," Chirurgie de la Main, vol. 27, no. 2-3, pp. 118-121, 2008.

[12] M. Mofidi, N. Kianmehr, D. Farsi, R. Yazdanpanah, S. Majidinezhad, and P. Asadi, "An unusual case of bilateral anterior shoulder and mandible dislocations," The American Journal of Emergency Medicine, vol. 28, no. 6, pp. 745.e1-745.e2, 2010.

[13] L. P. Silva, C. V. Sousa, E. Rodrigues, B. Alpoim, and M. Leal, "Bilateral anterior glenohumeral dislocation: clinical case," Revista Brasileira de Ortopedia, vol. 46, no. 3, pp. 318-320, 2011. 


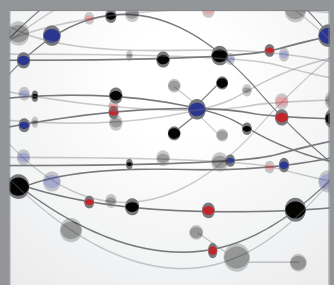

The Scientific World Journal
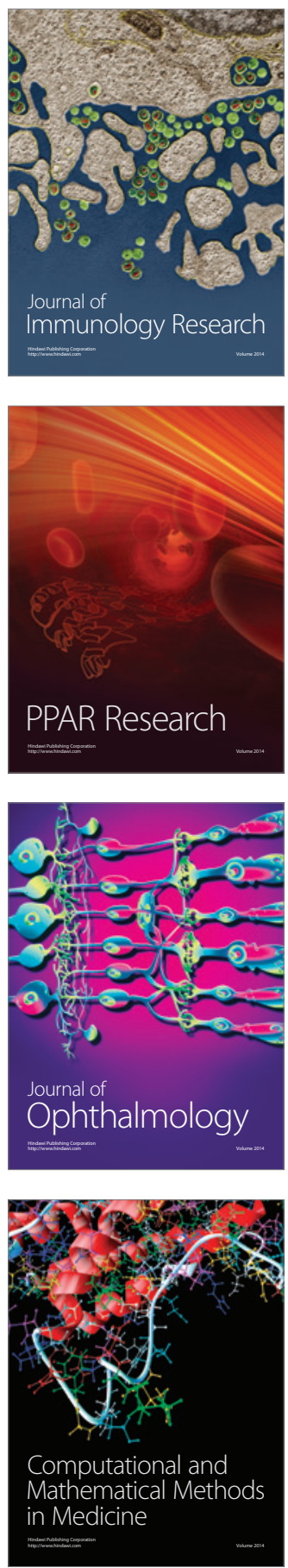

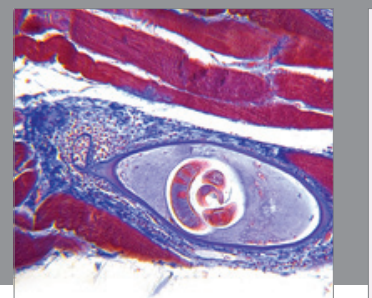

Gastroenterology

Research and Practice
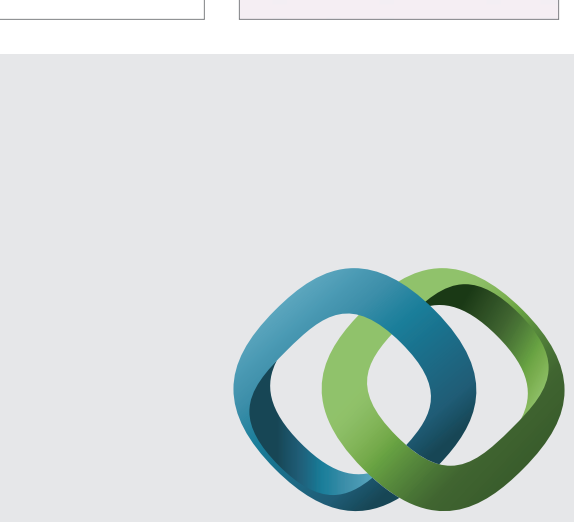

\section{Hindawi}

Submit your manuscripts at

http://www.hindawi.com
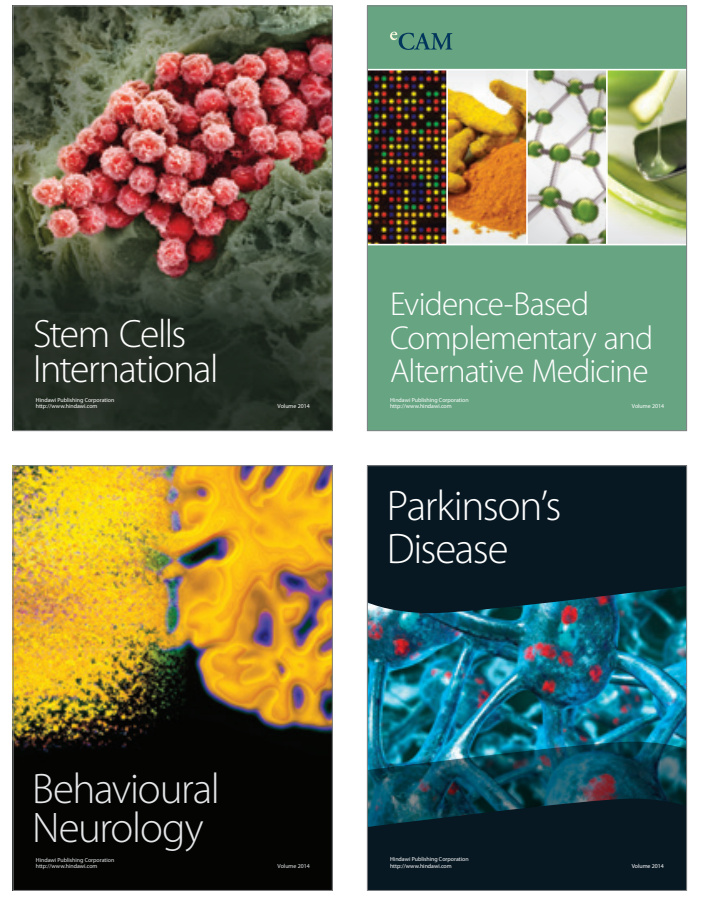
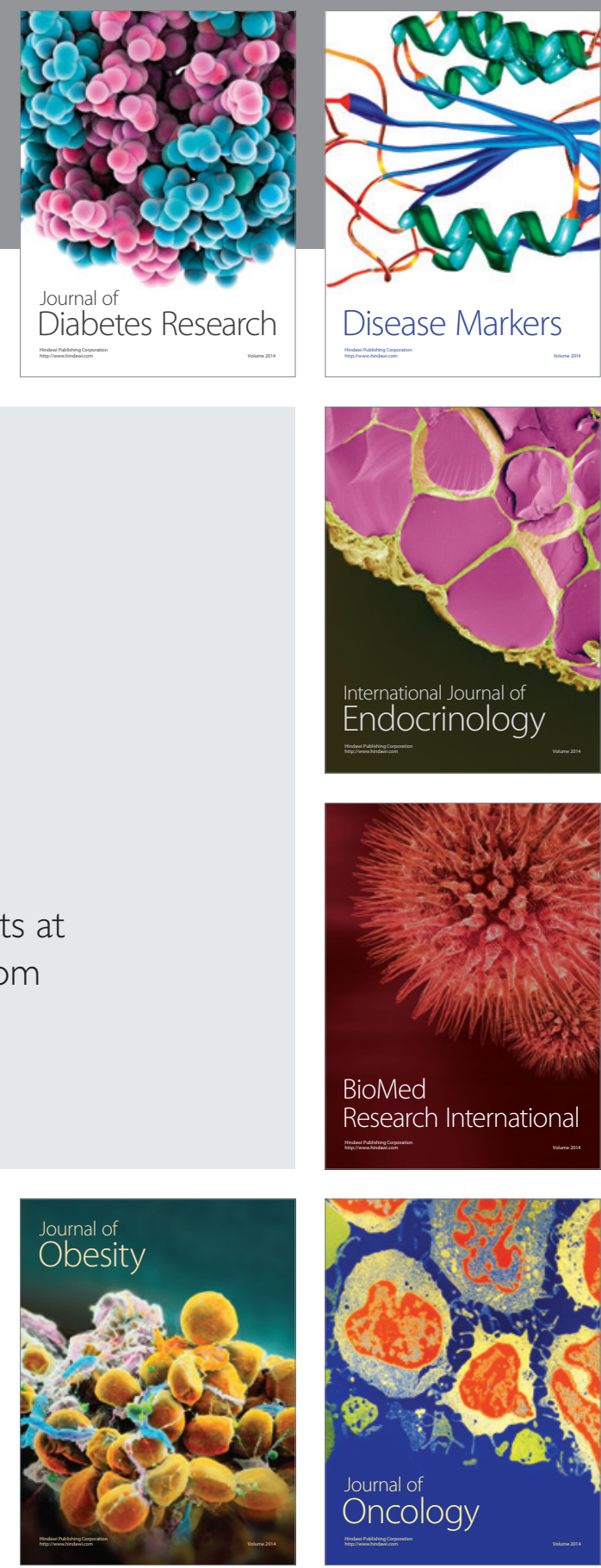

Disease Markers
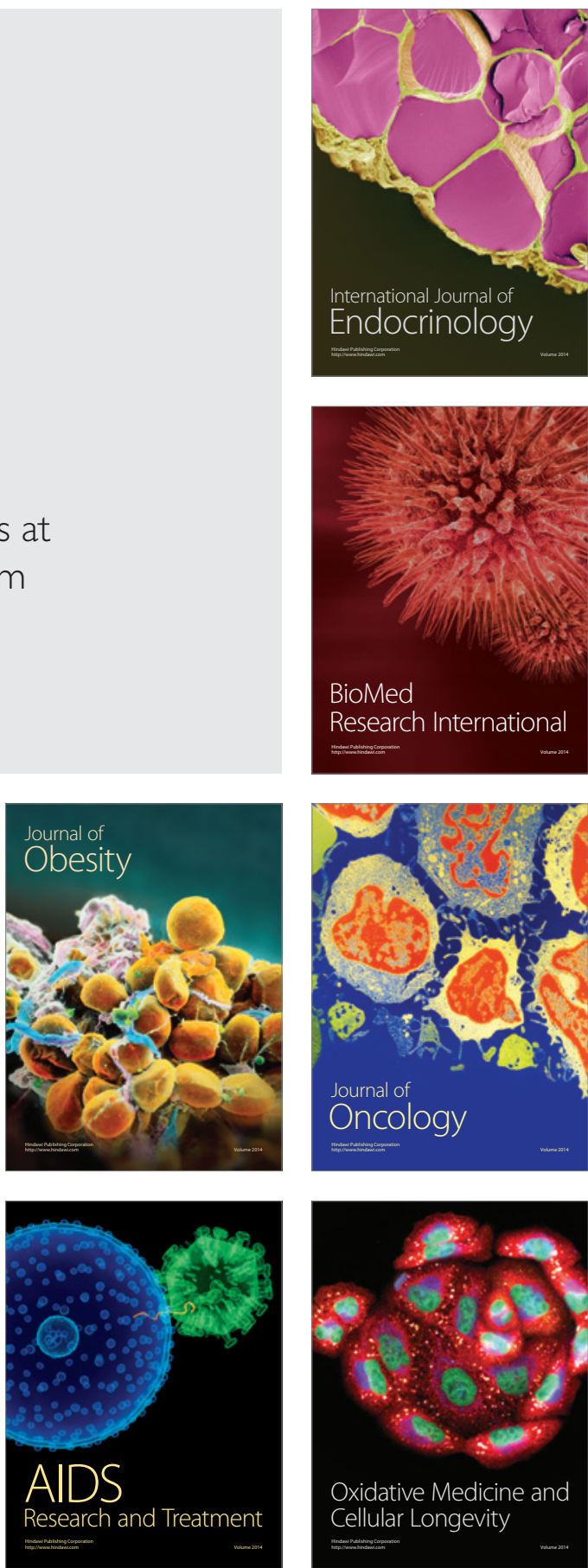